\title{
LAS CASAS COMO HISTORIADOR: HACIA UNA NUEVA INTERPRETACIÓN DE SU HISTORIA DE LAS INDIAS
}

\section{LAS CASAS AS HISTORIAN: TOWARD AN NEW NTERPRETATION ABOUT HIS HISTORY OF THE INDIES}

\author{
Hidefuji Someda*
}

\begin{abstract}
Este artículo trata de reconsiderar o reflexionar el valor histórico de la magna obra del padre Las Casas titulada Historia de las Indias, por medio del análisis de sus descripciones acerca de la isla Española, ya que dicha obra no solamente es una crónica, en que se mencionan minuciosamente los hechos de los conquistadores y pobladores españoles en los primeros años de la colonización de las Indias, sino también un testimonio histórico de la destrucción escrito por un testigo ocular desde el punto de vista de los vencidos.

Palabras claves: Extinción de los indios, la isla Española, esta isla Española, crónica, esclavos negros, utopía.
\end{abstract}

This article tries to reconsider or to reflect the historical value of magna book of Father Las Casas, titled Historia de las Indias, by means of analysis of his descriptions on the Hispaniola Island, because this work is not only a chronicle, in which the facts of the Spanish conquerors and settlers in the first years of the colonization of the Indians are mentioned meticulously, but also an historical testimony of the destruction written by an eyewitness from the point of view of the vanquished.

Key words: Extinction of the Indians, the Hispaniola Island, this Hispaniola Island, chronicle, negro slavery, utopia.

\section{Introducción}

Ha sido catalogada la Historia de las Indias de Las Casas como un testimonio fidedigno e indispensable para explicar la historia de los primeros años de la conquista y la dominación española en las Indias. En este sentido dicha obra puede ser considerada como invalorable documento histórico, igual que Historia general y natural de las Indias de Oviedo. Sin embargo, desde este punto de vista no podemos penetrar bien en la mentalidad del padre sevillano que describe tan repetidamente con detalles y mucha indignación la muerte de los naturales inocentes de la isla Española, que nos hace pensar que el autor sea un indio anónimo sobreviviente. En otras palabras la Historia de Las Casas es un testimonio acusatorio narrado por un historiador que pregunta sin cesar y hasta su fallecimiento el significado de la muerte de dichos isleños inocentes. De modo que para entender bien dicha obra monumental, es indispensable aclarar particularmente su visión sobre la isla Española.
En torno al apoyo que dio Las Casas a los colonos de la isla Española en sus últimos años

El conquistador alemán Nicolás Federmann, que pasó dos o tres años (desde 1529) en Santo Domingo de la Española, escribe que:

...es inútil hablar de los nativos o habitantes de esta tierra, porque han transcurrido cuarenta años desde que la isla fue conquistada y... casi todos han desaparecido... De los quinientos mil indios de varias naciones y lenguas que vivían en la isla cuarenta años atrás, apenas quedan veinte mil con vida. Un gran número murió de una enfermedad que ellos llaman viroles (sic. viruelas); otros perecieron en las guerras, otros en las minas de oro donde los cristianos les obligaron a trabajar en contra de su naturaleza, porque son gente delicada y poco trabajadores (Cit. en Lovell, W.G. y Cook, N.D. coord. 2000: 37).

* Universidad de Osaka. Osaka, Japón. Correo electrónico: h.someda@gmail.com 
Y casi 15 años después, en 1548, el adversario implacable del padre Las Casas, Gonzalo Fernández de Oviedo declara que "no se cree que hay al presente en este año de mil e quinientos y quarenta e ocho, quinientas personas, entre chicos e grandes, que sean naturales e de la progenie o estirpe de aquellos primeros..." (Oviedo 1959: 66-67). Finalmente, hacia principios de la década de los cincuenta del siglo XVI, el insigne "príncipe de los cronistas", Cieza de León nos lega, como testigo ocular, un testimonio de la situación desastrosa de dicha isla caribeña, al escribir que:

E no enbargante que yo sé, por la esperiençia que tengo del tiempo largo que residí naturales, que no asi ligeramente se podrían decir, pues todos saben quán poblada fue la isla Española, e que si los cristianos con modestia se ovieran con los naturales e los trataran como a próximos, ciertamente obiera en ella mucho número dellos, e agora no queda otro testimonio de aver sido poblada que las grandes sepulturas de los muertos y asientos de los pueblos donde bibieron;... (Cieza de León 1994: 351).

De estos tres testimonios se ve con claridad que hacia mediados del siglo XVI, la isla Española estaba completamente despoblada de nativos, de lo que se enteró bien nuestro padre sevillano, quien ya escribió en 1542 en el borrador del polémico tratado titulado Brevísima relación de la destrucción de Indias que “...habiendo en la isla Española sobre tres cuentos de ánimas que vimos, no hay hoy de los naturales della docientas personas" (Las Casas 2009: 11). Es decir, que ya a mediados del siglo XVI, para los españoles, ya fueran conquistadores, pobladores, oficiales o religiosos que habían estado en las Indias, la extinción de los naturales de la isla era un hecho irrefutable e inconfundible.

A pesar de eso, Las Casas, hombre que debería de conocer mejor que nadie la situación misérrima e irremediable de la isla Española, escribió, en la segunda mitad de la década de los cincuenta, dos cartas referentes a ella: una destinada al príncipe Felipe con fecha del 20 de junio de 1555 y, la otra, datada el 20 de febrero de 1559 y dirigida al mismo personaje, pero que ya había heredado el trono de la monarquía como Felipe II. En la primera, nuestro padre menciona que la isla padece grandes necesidades y tiene que ser inmediatamente remediada (Las Casas 1995: 277). Y en la carta de 1559, Las Casas, enfatizando la riqueza y felicidad de la isla, propone una medida concreta para remediarla, como sigue:

Entre las otras cosas que yo he deseado mucho dar a entender a Vuestra Majestad es el valor, y riqueza y feliçidad de la isla Española, si Vuestra Majestad se desocupase para tener della más cuidado y del remedio que le es no sólo conveniente, pero neçesario... El remedio della y todo lo dicho es poblarla de gente labradora y llana, que en estos reinos sobra. Y esto digo que se hará con que no gaste Vuestra Majestad quince o veinte mil ducados cada año y no más de por diez años, y hará en ello Vuestra Majestad un gran reino mayor que el de España, que en pensallo tiemble el rey de Francia (Las Casas 1995: 329-330).

Así, nuestro padre sevillano explica la necesidad de repoblar la isla con labradores de Castilla, lo que nos hace recordar el plan que había propuesto e intentado poner en práctica casi 40 años antes para remediar las realidades catastróficas de las Indias. Y es bien sabido que esos primeros proyectos de reforma indiana por medio de la emigración de labradores castellanos y de su convivencia pacífica con los indios resultaron fracasados: prueba de ello es el caso bien conocido de la colonización pacífica en Cumaná de la Venezuela actual (1521-22). Entonces, ¿podría decirse que esta propuesta de repoblación de la isla Española, presentada por Las Casas a Felipe II hacia finales de la década de los cincuenta del siglo XVI, era anacrónica y sin sentido?

Bien, a mi modo de ver, a dicha propuesta de Las Casas en sus últimos años solo dos lascasistas han prestado atención particular, quienes son los historiadores franceses. Uno es el profesor Bernard Lavallé de la Universidad de Sorbona, y el otro, el erudito e insigne hispanista del siglo pasado, Marcel Bataillon.

Ahora vamos a echar un vistazo a la interpretación del historiador francés Bernard Lavallé acerca de las dos cartas de Las Casas en cuestión.

Lavallé, en la obra biográfica titulada Bartolomé de Las Casas. Entre la espada y la cruz, trata de dichas cartas en el capítulo 11, titulado "De Carlos I a Felipe II: la época de las incertidumbres" 
(2009: 219-235). El profesor de la Universidad de Sorbona explica que Las Casas escribió esas cartas en apoyo de un tal Baltasar García, enviado por la municipalidad de Santo Domingo y emisario de los colonos de la isla Española, quienes reclamaban la inmigración blanca y la licencia para introducir sin impedimentos fiscales más esclavos africanos en la isla, donde la economía azucarera se encontraba en una situación crítica debido a la falta de inversiones, de mercados y de mano de obra. Y Lavallé, refiriéndose al plan lascasiano de repoblación de la isla, dice que ahí "reaparece la mentalidad juvenil, la que organizaba proyectos de asentamientos de gente española, laboriosa y sencilla" (Lavallé 2009: 234), y afirma que el objetivo de Las Casas "no era el enriquecimiento (de los colonos) a toda costa sino una vida ejemplar y armónica en la que servirían de modelos y tutores de los indios" (2009: 234). Pero el profesor francés, al tomar en cuenta el hecho irrefutable de que en la Española ya no había indios, se ve obligado a afirmar lo siguiente:

Las Casas, ya muy anciano en aquella época, presentaba también signos de un visible desfase con respecto a la nueva realidad americana, como lo demostró el apoyo precipitado, o incluso imprudente, que brindó a los trámites del procurador de Santo Domingo, Baltasar García (Lavallé 2009: 235).

Así, Lavallé, bajo la premisa de que el padre sevillano era muy anciano y ya no podía reconocer bien la "nueva" realidad de las Indias, concluye apresuradamente que la intervención o ayuda positiva de Las Casas en los trámites del procurador de Santo Domingo fue "imprudente". Pero como se ve con claridad en las actuaciones vitales que nuestro padre desarrolló desde su último regreso de las Indias a España (1547) hasta su fallecimiento de 1566, como la redacción de dos obras referentes al Perú tituladas De Thesauris y Doce Dudas, nuestro padre sigue manteniéndose bien enterado y preocupado de la realidad indiana en transición, la que, a su modo de ver, se orientaba hacia una dirección totalmente opuesta a la predestinada por Dios, esto es a la salvación eterna de los indios. Por consiguiente podemos afirmar que la interpretación del profesor francés es excesivamente simplista y subjetiva, carente de fundamento.
Entonces nos queda referirnos a la interpretación de aquel gran hispanista Bataillon. Él escribió en 1959 un artículo muy interesante titulado "Estas Indias... (hipótesis lascasianas)"1, en que planteó algunas cuestiones acerca de la magna obra del padre sevillano titulada Historia de las Indias, y propuso algunas hipótesis. Una de ellas se refiere a la razón por la que Las Casas empleó el demostrativo de primera persona "esta (isla)" en la Historia de las Indias al referirse a la isla Española, a pesar de que se dedicó a redactar dicha voluminosa obra con mucho ahínco en la metrópoli a partir de 1552. Como bien señala el gran erudito francés, Las Casas en la Historia de las Indias sustituye, excepto en unos pocos casos, el artículo de la isla Española por el demostrativo de primera persona. Bastará citar aquí tres ejemplos:

1) Manifiesto es, por infinitos testimonios y argumentos arriba traídos, la mansedumbre y pacífica y modesta natural cualidad y condición de los habitadores naturales desta isla, y las pocas y leves y cuasi ningunas armas que tenían... (Las Casas 1951: 203).

2) ...y así se fueron consumiendo las multitudes de vecinos y gentes que había en esta isla, que según el Almirante escribió a los reyes, eran sin número...y en tiempo de los dichos ocho años de aquel gobierno perecieron más de las nueve de diez partes. De aquí pasó esta red barredera a la isla de Sant Juan y a la de Jamaica y después a la de Cuba... (Las Casas 1951: 257).

3) En este mismo año y en estos mismos días que el padre fray Pedro de Córdoba fue a la Vega, había cantado misa nueva un clérigo llamado Bartolomé de las Casas, natural de Sevilla, de los antiguos de esta isla, la cual fue la primera que se cantó nueva en todas estas Indias; y por ser la primera, fue muy celebrada y festejada del Almirante y de todos los que se hallaron en la ciudad de la Vega, que fueron gran parte de los vecinos desta isla...(Las Casas 1951: 385-386)

Bien, ahora veamos la hipótesis de Bataillon, que dice:

El demostrativo de primera persona sustituido al artículo de las Indias, la isla Española o la ciudad de Santo Domingo no significa de ninguna manera que el trozo correspondiente se escribiese allí. Pero es demasiado constante para ser 
causal, tratándose de obras redactadas en España. Obedece a otra intención, y lo más probable es pensar que Las Casas, que desde 1547 hasta su muerte (1566) no volvió a salir de España, emprendió en 1552 y prosiguió hasta 1560 la redacción de sus dos obras más extensas con la idea fija de que habían de publicarse y leerse en la isla Española, más exactamente en Santo Domingo (Bataillon 1976: 295).

Y refiriéndose a las dos cartas en cuestión de Las Casas, Bataillon concluye argumentando su hipótesis del modo siguiente:

Las Casas escribe al rey desde Valladolid el 20-V-VI-1555 y el 20-II-1559, cuyo contenido demuestra el afán con que el anciano reformador proponía un plan de repoblación agrícola de la gran isla Española. Encarece su valor y riquezas y felicidad y su importancia capital como llave de todas las Indias. En 1559 suplica a Felipe II que ponga dueño a aquellas Indias, pues son suyas, porque cierto no lo tienen. ¿No podrá relacionarse con estas perspectivas el sueño de que saliese a luz la Historia en Santo Domingo nueva capital imperial? (Bataillon 1976: 299).

Así, el gran hispanista francés intenta ver en esas dos cartas la postura pragmática o política de Las Casas como reformador infatigable de las Indias, función que desempeñaba a partir de su primera conversión de 1514, y el interés o atención que mantenía invariablemente por la isla Española. Está de más decir que esta hipótesis de Bataillon es persuasiva y está respaldada por sus largas y serias investigaciones académicas, pero aunque a juzgar del Prólogo de la Historia de las Indias, que escribió Las Casas hacia 1552, es innegable que nuestro padre tenía originalmente la intención de publicarla, no podemos aceptar incondicionalmente la hipótesis de Bataillon. Porque Las Casas, unos nueve meses después de haber escrito a Felipe II la carta de que tratamos, es decir, en noviembre de 1559, legó los manuscritos de la Historia de las Indias al Colegio de San Gregorio de Valladolid, escribiendo que:

... rogando y pidiendo por charidad al padre rector y consiliarios dél, que por tiempo fueren, que a ninguna seglar la den para que, ni dentro de dicho colegio, y muchos menos de fuera dél, la lea por tiempo que quarenta años, desde este de sesenta que entrará, començados a contar. Y pasados aquellos quarenta años, si vieren que conviene para el bien de los indios y de España; la pueden mandar imprimir para gloria de Dios y manifestación de la verdad principalmente (Las Casas 1955: 331).

De dichas palabras, no sería gran error afirmar que Las Casas, cuando estaba a punto de terminar la redacción de la Historia de las Indias, ya no tenía intención de imprimirla ni darla al público no solo en España sino tampoco en la isla Española, por lo que nos vemos precisados a afirmar que la interpretación de Bataillon acerca de la sustitución del artículo de la isla Española por el demostrativo de primera persona no es acertada, ni está suficientemente documentada. O sea, que el uso de dicho demostrativo no tiene nada que ver con la intención de publicar la obra en la isla Española, sino que más bien tiene un sentido más importante para analizar el pensamiento de Las Casas en sus últimos años, o mejor dicho para entender bien la Historia de las Indias y aclarar la actualidad de Las Casas como "historiador".

Bien, entonces volvamos al tema. Como hemos visto, Las Casas, al referirse a la isla Española en esas dos cartas, a diferencia de la Historia de las Indias, no emplea el demostrativo de primera persona, sino el artículo determinado o el demostrativo de tercera persona ("la isla" o "aquella isla"). Por lo tanto creo que vale la pena examinar aquí qué categoría gramatical usa Las Casas en sus otros escritos al mencionar dicha isla. Bastará citar dos ejemplos: uno está tomado de Entre los remedios o conocido como el Octavo remedio (1542), y el otro de Doce Dudas (1564). En el primero, nuestro padre, para demostrar la ilegitimidad de la encomienda y solicitar su total e inmediata derogación, refiriéndose a la isla Española afirma que:

La oncena razón es porque la dicha encomienda de dar los indios a los españoles siempre caresció de autoridad de los reyes, y el que primero la inventó, repartiendo los indios generalmente entre los españoles como si fueran hatajos de ganados en la isla Española, y por repartirlos así toda la 
isla despobló y asoló, nunca tuvo poder para hacerla y excedió los fines y términos del mandado, y, por consiguiente, siempre fue en sí ninguna y de ningún valor... (Las Casas 1965: 766-767).

Y en las Doce Dudas Las Casas escribe como sigue:

Otrosí, parece que los indios no se encomienden de aquí en adelante a ningunas personas, e que todas las encomiendas hechas se quiten luego..., por las experiencias que se tiene de las crueldades o excessivos trabajos y falta de mantenimientos, o en el tratamiento que les han hecho y hacen sufrir, siendo hombres libres, donde resulta acabamiento y consumación de los dichos indios y despoblación de la tierra, como se ha hecho en la Española (Las Casas 1993: 150).

Como muestran estos dos ejemplos, podemos señalar que generalmente nuestro padre no utiliza el demostrativo de primera persona para referirse a la isla Española en los opúsculos o memoriales "políticos", tales como Brevísima Relación de la Destrucción de las Indias y Entre los remedios, en los que el padre dominico propuso unas medidas concretas para la reforma de las Indias, como la suspensión inmediata de la conquista, la derogación total de las encomiendas o la prohibición de la esclavización de los indios. Tampoco lo utiliza en los tratados llamados "teóricos", como Doce Dudas y De Thesauris, donde manifestaba sus propias doctrinas teológico-jurídico-políticas basándose no solo en las autoridades cristianas de la Edad Media o la Contemporánea, sino también en las autoridades grecolatinas en la Antigüedad. Pero por otra parte, tenemos que tener en cuenta el hecho de que en su otra magna obra "antropológica", titulada Apologética Historia Sumaria, Las Casas sí usa el demostrativo de primera persona al referirse a la isla Española. Veamos solo dos ejemplos:

1) Para tractar, pues, en suma, la disposición, descripción y calidades destas regiones, reinos y provincias, y las condiciones naturales, policías y costumbres de las gentes y naturales habitadores dellas, parecióme comenzar por esta isla Española, pues fue primero que lo demás, de lo principal hablando, descubierta, y su excelencia, bondad, fertilidad y grandeza merece, cuanto a ser isla, que a todas las tierras sea prepuesta (Las Casas 1951: 10).

2) Supuesto, pues, que fueron gobernadas y regidas por uno que es rey, comencemos a ejemplificar, como solemos, por esta felicísima isla Española... Había en esta isla y en cada reino della muchos nobles y estimados por de mejor sangre que los demás, y que tenían cargo sobre otros como de regillos y guiallos... (Las Casas 1951: 308-309).

Es natural que en la Apologética Historia Sumaria Las Casas sustituya el artículo determinado de la isla Española por el demostrativo de primera persona, ya que, como es bien sabido, el padre sevillano originalmente intentaba escribir "una" crónica en que se habían de tratar la historia general y la historia natural de las Indias, y en el proceso de redacción, hacia 1556, decidió dividirla en dos obras, que son la Historia de las Indias y la Apologética Historia Sumaria. Es decir, que Las Casas utiliza la expresión de "esta isla Española" exclusivamente en dos obras citadas, lo que nos sugiere que dicha isla caribeña había llegado a ser un espacio muy especial en la mentalidad o pensamiento de Las Casas en sus últimos años.

Bien, ahora sería conveniente aclarar qué categoría gramatical (qué demostrativo) utilizan otros cronistas contemporáneos en el caso de dicha "isla Española". A tal efecto, primero recordemos la frase de Cieza de León antes citada y que es: “...pues todos saben quán poblada fue la isla Española...”. $\mathrm{Y}$ ahora veamos otras crónicas:

1) "Todos o la mayor parte de los de la isla Española, tienen muchos cemíes de diversas suertes..." (Pané 1974: 34).

2) "Veo que nuestros isleños de la Española son más felices que aquellos..." (Mártir de Anglería 1989: 23).

3) "Los naturales de la Española auían mostrado al Almirante minas de oro antiguas,..." (Oliva 1965: 89).

4) "Luego los mercaderes los llevan a otros lugares y los venden. A otros los llevan a la Española..." (Benzoni 1989: 76).

Así, vemos que en otras crónicas suele ser empleado el artículo determinado ("la"), lo que 
quiere decir que en ellas dicha isla es tratada de modo objetivo, solo como un espacio histórico donde los españoles desarrollaron sus empresas indianas. Pero hay un cronista que utiliza el demostrativo de primera persona al referirse a la isla Española, y es Gonzalo Fernández de Oviedo, que trata de ella en muchos lugares de su voluminosa obra titulada Historia general y natural de Indias. Bastará citar dos ejemplos:

1) Hase dicho en el precedente capítulo la forma de las camas de los indios desta Isla Española. Dígase del complimiento dellas, que es el matrimonio que usaban; puesto que, en la verdad, este acto que los cristianos tenemos por sacramento, como lo es, se puede decir en estos indios sacrilegio... (Oviedo 1959: 118 ${ }^{\mathrm{a}}$ ).

2) En el capítulo antes déste, nombré los ríos principales e poderosos que hay en esta isla Española, e pasé brevemente por ellos. Quiero agora decir de algunos, que también los nombré, que no son famosos por grandeza e profundidad de agua ni de tantas pesquerías; pero sónlo, mucho más que todos los que he dicho, por la abundancia del oro... (Oviedo 1959: 154 $4^{\mathrm{a}}$ ).

Así, Oviedo, igual que Las Casas en la Historia de las Indias, la llama “esta isla". Aquí es de notar que quien a la isla Española la llama espontánea o inconscientemente "esta isla", deberá ser "isleño", es decir, natural de dicha isla, o autor que estando en dicha isla escribe y redacta manuscritos referentes a ella. Por supuesto que Oviedo no fue isleño, lo que quiere decir que para Oviedo la isla Española no es más que un espacio histórico, el espacio en que escribía como cronista, viviendo allí enviado como funcionario real y superponiendo su vida al presente y al futuro de la isla, en la que ya solo habitaban los colonizadores españoles y los esclavos negros después de la extinción de los indígenas. Mientras tanto, como he dicho, es en la metrópoli donde Las Casas se dedica a escribir y redactar con toda su alma la Historia de las Indias a partir de 1552, aunque empezó a escribirla en la isla Española hacia la segunda mitad de la década de 1520. De ahí que es innegable que Las Casas utiliza "conscientemente" el demostrativo de primera persona como sustituto del artículo determinado al referirse a dicha isla caribeña. Por lo tanto podemos afirmar que entre Las Casas y Oviedo hay gran abismo en el modo de reconocer la realidad de las Indias, es decir, la historia contemporánea, y en el modo de narrarla como historiador. $Y$ ese abismo lo podemos percibir bien si escuchamos la acusación que lanza Las Casas contra Oviedo:

... el pago que Oviedo les da a los (indios) que él consumió y ayudó a destruir e por los otros que destruyeron tantos millares de gentes, es infamallos para siempre, ya que no les puede ni pueden hacer más mal, y que los echó y echaron a los infiernos (Las Casas 1951: 333-334).

Entonces nos queda la tarea de aclarar la intención con que Las Casas escogió tal forma de expresión. Es decir, que tenemos que reflexionar acerca del sentido histórico que tendría la isla Española en el pensamiento de Las Casas en sus últimos años. A este efecto no es necesario tratar la Historia de las Indias como una crónica en que se menciona con todo detalle el proceso de las empresas indianas de los españoles en sus primeros treinta años; ni como una biografía que aclara las actividades del autor en su juventud, sino que más bien nos vemos obligados a leerla como el testimonio de un testigo ocular de la realidad indiana (la destrucción de la isla Española), testigo que se transformó de conquistador en fraile luchador infatigable por la libertad de los indios, pasando por un período como colonizador-clérigo; porque la sustitución "intencionada" del artículo determinado por el demostrativo de primera persona acerca de la isla caribeña nos exige leer e interpretar la Historia de las Indias de modo totalmente distinto de las otras crónicas contemporáneas o posteriores, como Historia natural y general de las Indias de Oviedo e Historia natural y moral de las Indias del padre José de Acosta, entre otras.

Pues bien, no sería error afirmar que en la Historia de las Indias Las Casas trata principalmente de tres personajes y de tres espacios históricos, que serían elementos claves de los que no debemos hacer caso omiso para entender y evaluar su obra. En cuanto a aquellos, no dudamos en decir que el primer personaje es el almirante Cristóbal Colón. El segundo es el autor mismo, pero no presentado en la primera persona, sino en la tercera persona como "el clérigo Las Casas", es decir, el Las Casas "de antes", el que desde que había cantado la primera misa en la Vega de la Concepción (1510) se dedicaba a la lucha por la defensa de los indios con toda su 
buena voluntad derivada del espíritu cristiano, lucha que desplegó a ambos lados del océano Atlántico hasta su "segunda conversión" de 1523 (es decir, hasta la entrada en la Orden de Predicadores). Aquí vale la pena citar cuatro ejemplos para entender el significado del cambio en el modo de narrar respecto de sí mismo.

1) En este tiempo prendieron (los españoles) ciertos señores principales, y mandólos el capitán general (Juan de Esquivel) quemar vivos; $y$ creo que fueron cuatro, porque de tres no tengo que dudar. Para quemallos hicieron ciertos cadalechos sobre cuatro o seis horquetas, puestas unas varas a manera de parrillas y en ellos los caciques muy bien atados; debajo pusieron muy buen fuego y comenzándose a quemar, daban gritos extraños, que oírlos las bestias me parece que no los pudieran tolerar. ...Todo esto yo lo vide con mis ojos corporales mortales (Las Casas 1951: 265-266).

2) Diego Velázquez envió a mandar a Pánfilo de Narváez, ...que fuese a la provincia de Camagüey, ... y que fuese aquel padre clérigo Bartolomé de las Casas con él, y creo que le escribió a él que lo hiciese ...El clérigo Casas, luego en llegando al pueblo, hacía juntar todos los niños chiquitos, y tomaba dos o tres españoles que le ayudasen, con algunos indios desta isla Española, ladinos, que consigo llevaba y algunos que abía él criado, baptizaba los niños que en el pueblo se hallaban... Por esta vía ...cobró mucha estima y crédito en toda la isla con los indios...; por este crédito y auctoridad que había entre ellos cobrado, no era menester ir delante, sino enviar un indio con un papel viejo, puesto en una vara, enviándoles a decir con el mensajero que aquellas carttas decían esto y esto, conviene a saber, que estuviesen todos quietos y ningún se absentase, porque no se les haría mal ni daño, y que tuviesen de comer aparejado para los cristianos, y los niños para baptizar..., y todo lo que parecía envialles a avisar, y que si no lo hacían, se enojaría el padre, y ésta era la mayor amenaza que se les podía enviar (Las Casas 1951: 534-535).

3) En este tiempo, muchas más cosas y mejores provisiones y más ciertos remedios para los indios (supuesto siempre el primero que es el verdadero, conviene a saber, ponellos en libertad, sin el cual ninguno hay bueno), y para que los españoles pudieran vivir sin tener indios en estas islas, se despacharan y el cardenal (Cisneros) los proveyera, si el clérigo Casas hobiera más pensado en ello y se las notificara, como después, andando en los negocios, alcanzó, según el crédito que el cardenal le daba, pero como poco había que lo había considerado, y la tiranía estaba tan entablada y arraigada, y anduvo en el negocio, como en cosa nueva y escandalosa, paso a paso y como acobardado, harto pensó que había bien negociado en poner los indios en libertad, sacándolos del poder del diablo, y ya que esto no se efectuara, ser causa de enmendar todas as dichas leyes, para estorbar algo de la opresión que los indios padecían, según los males que eran grandes (Las Casas 1951: 135).

4) Este aviso de que se diese licencia para traer de España una docena, más o menos, de esclavos negros a estas tierras dio primero el clérigo Casas, no advirtiendo la injusticia con que los portugueses los toman y hacen esclavos; el cual, después de que cayó en ello, no lo diera por cuanto había en el mundo, porque siempre los tuvo por injusta y tiránicamente hechos esclavos, porque la misma razón es dellos que de los indios (Las Casas 1951: 177).

Así, Las Casas, cuando trata en primera persona de la realidad catastrófica de las islas caribeñas, la narra como testigo ocular ("vide yo") o como un juez encargado por Dios de dar sentencia a los culpables, pero cuando trata de sí mismo en tercera persona, se censura a sí mismo con mucha vehemencia como cómplice de las crueldades y atrocidades cometidas por sus paisanos, y revela con mucho remordimiento su ignorancia y ceguedad de la realidad histórica contemporánea, pues que había propuesto a la Corona la introducción de esclavos negros en las Indias para reemplazar a los indios en los trabajos tremendamente pesados. Esta forma de autorreflexión y autocrítica nos aconseja leer y entender la Historia de las Indias como un "testimonio-confesión", escrito y redactado no para unos supuestos lectores, sino más bien para Dios y los sacrificados bajo pretexto de cristianización, es decir, los indios.

Y el tercer y último "personaje" de que trata Las Casas como elemento clave en la Historia de las Indias es la corte metropolitana, en otras palabras, las personas que forman el núcleo de 
la gobernación de las Indias, los beneficiarios de los asuntos de las Indias y los intelectuales que se agrupaban en la corte. Es decir, que son los Reyes Católicos, Francisco Ximénez de Cisneros, Lope de Conchillos, Francisco de los Cobos, Juan Rodríguez de Fonseca, Pedro Mártir, Palacios Rubios y Fernández de Oviedo, entre otros.

Tratemos ahora de los tres espacios históricos que serían elementos claves en la obra de Las Casas. El primer espacio es África, o mejor dicho la África occidental y sus islas litorales, incluyendo las Canarias. Está de más decir que este espacio ocupa un lugar importante en la Historia de las Indias, está demostrado por el hecho de que Las Casas, acosado por la culpabilidad de su imprudencia, ignorancia y ceguedad acerca de la realidad de la esclavización de negros por los portugueses en África, se vio precisado a describir y censurar dicha realidad en tantos capítulos que, según algunos investigadores, constituirían un tratado que se llamaría "Brevísima Relación de la Destrucción de África".

Y por supuesto que el segundo espacio histórico que podemos considerar como uno de los elementos claves en la Historia de las Indias son las Indias mismas. Para nuestro padre las Indias serían el espacio donde habría de ser realizada la voluntad divina, es decir, la edificación del nuevo reino del cristianismo o la salvación eterna de los naturales de ellas. Aquí es de recordar que, como señaló Marcel Bataillon, en la Historia de las Indias, igual que en el caso de la isla Española, Las Casas sustituye el artículo determinado por el demostrativo de primera persona al referirse a las Indias. Veamos unos ejemplos:

1) Fue regla general que los indios de los repartimientos que daban para la granjerías del rey eran siempre los más cruelmente por sus oficiales afligidos y tractados, y así más aína que otros perescían en todas las partes destas Indias, y hoy lo son más opresos y más malaventurados (Las Casas 1951: 391).

2) Referidas y explanadas quedan las cosas, que dignas fueron de poner en historia, acaecidas en estas Indias, desde su descubrimiento, por enteros diez y ocho años, contados desde el de 1492 hasta el entero año de 519... (Las Casas 1951: 432).

3) Y porque los españoles llegando al pueblo, hallando los indios en sus casas pacíficos, no cesaban de les hacer agravios y escandalizallos..., no contentándose con lo que de su voluntad los indios daban, y algunos más adelante, andaban tras las mujeres y las hijas, porque ésta es y ha sido siempre la ordinaria y común costumbre de los españoles en estas Indias... (Las Casas 1951: 534).

Entonces no sería un gran error identificar la intención de Las Casas de llamar a las Indias "estas Indias" con la de llamar a la isla Española "esta isla Española", porque Las Casas, en la carta de 20 de junio de 1555, escribe que la isla Española es "la llave de todas las Indias". Si esto es así, podemos decir que, según Las Casas, la isla Española debería ser punto de partida para la realización de la voluntad divina en todas las Indias, porque para el fraile dominico la isla era un espacio histórico especial, elegido por Dios para que fuera el primer lugar de donde había de expandirse la fe cristiana a todas las Indias. Es decir, según Las Casas, a sus habitantes solo les faltaba creer en Dios. En otras palabras, para Las Casas, la isla Española fue al principio un lugar ideal, como si fuera una "utopía", en que solo habría de ser introducido el cristianismo, pero después se convirtió pronto en un infierno, donde se desarrollaron en gran escala las crueldades y atrocidades de los españoles y fueron aniquilados sus habitantes. Es decir, que la isla Española se transformó de "utopía" en la isla totalmente despoblada de indios, es decir, en "la isla de los muertos". Es seguro que ya a mediados del siglo XVI la isla Española le parecía a Las Casas como una utopía destruida. Tal proceso de transformación drástica de la isla lo presenció Las Casas durante casi treinta años como testigo ocular, primero como conquistador, después como colonizador-clérigo y finalmente como el fraile luchador incansable por la libertad de los indios. Aquí no es de olvidar que Las Casas empezó a escribir y redactar la Historia de las Indias después de experimentar durante casi diez años (1542-1552) una vida colmada de vicisitudes como promotor de las Leyes Nuevas, obispo de Chiapas y controversista con Ginés de Sepúlveda en Valladolid. Es así que no es difícil deducir que en nuestro padre, quien vio por sus propios ojos dicho proceso de transformación de la isla Española en isla de los muertos, y que por medio de tal experiencia inaudita se convenció de la imposibilidad de las reformas indianas debido a la ignorancia, ceguedad e imprudencia de los españoles cristianos, dicha isla llegase a ocupar un lugar muy especial no solo como punto de partida de las conquistas, sino también como un espacio absoluto 
que juzga y juzgará para siempre las conquistas y sus agentes. Por consiguiente, es natural que Las Casas, en la Historia de las Indias, trate largamente de la historia de África, juzgue a Cristóbal Colón y a sí mismo, y dé muchos testimonios minuciosos relativos a la destrucción de la isla Española, que se convierte así en el tercer espacio histórico clave en la obra.

Pensando así, podemos decir que la frase "esta isla Española" demuestra que Las Casas, aunque no fue isleño, intenta acercarse con todo esfuerzo a los indios de dicha isla y testimonia, en lugar de los muertos, el proceso de su despoblación. En este sentido la Historia de las Indias es una obra totalmente distinta no solo de sus otros escritos políticos o teóricos, sino también de las otras crónicas contemporáneas, como las de Fernández de Oviedo, Cieza de León y López de Gómara, en las que quienes son tratados como protagonistas dignos de ser elogiados son los conquistadores españoles. Así, la frase "esta isla Española" nos permite afirmar que Las Casas es un historiador singular que narró la historia como un juicio dado por los muertos y que pudo criticar radicalmente la concepción contemporánea de la historia, según esta se consideraba la historia como narración de hazañas. Por consiguiente no sería gran error concluir que para nuestro padre la isla Española es un espacio histórico tan importante y especial en las Indias ("llave de todas las Indias") que le hizo reflexionar profundamente acerca del sentido histórico de la muerte de los naturales y, adquirir el modo de ver, reconocer y narrar la historia contemporánea. En una palabra, dicha isla Española sería la madre que ha dado a luz al historiador Las Casas.

\section{Conclusiones}

Las Casas, enterado bien de la realidad histórica de la isla Española, llegó en sus últimos años a reflexionar profundamente acerca del significado de escribir la historia contemporánea como testigo ocular, y se transformó de un indigenista infatigable en un historiador universal que trata de crear una nueva historia de la humanidad, que fuera distinta de la que describieron los cronistas contemporáneos.

\section{Referencias Citadas}

Benzoni, Jerónimo

1967[1566] La Historia del Mundo Nuevo. Traducida por Carlos Radicati di Primeglio. Universidad de San Marcos, Lima.

Cieza de León, Pedro de

1994[¿1552?] Crónica del Perú. Cuarta Parte. Vol. II Guerra de Chupas. Edición, prólogo y notas de Gabriela Benavides de Rivero, Pontificia Universidad Católica del Perú y Academia Nacional de Historia, Lima.

Las Casas, Fray Bartolomé de

1995 Cartas y Memoriales. Obras Completas Nº 13. Edición preparada por la Fundación Instituto Bartolomé de Las Casas, de los Dominicos de Andalucía. Director de la edición: Dr. Paulino Castañeda Delgado. Alianza Editorial, Sevilla.

Las Casas, Fray Bartolomé de

1995[¿1564?] Doce Dudas. Obras Completas No 11.2, Edición de J.B. Lassegue, O.P., Estudio preliminar, índices y bibliografía de J. Denglos. Alianza Editorial, Sevilla.

Las Casas, Fray Bartolomé de

1951[¿1562?] Historia de las Indias. II. Edición de Agustín Millares Carlo y estudio preliminar de Lewis Hanke. Fondo de Cultura Económica, México.
Lovell, W. George y Cook, Noble David coord.

2000 Juicios secretos de Dios. Epidemias y despoblación indígena en Hispanoamérica colonial. Traducido por Jorge Gómez. Abya-Yala, Quito.

Mártir de Anglería, Pedro 1989 Décadas del Nuevo Mundo. Crónicas y Memorias. Madrid.

Oliva, Hernán Pérez de

1965 Historia de la Inuencion de las Yndias. Estudio, edición y notas de José Juan Arrom. Bogotá.

Oviedo, Gonzalo Fernández de

1959[1536] Historia general y natural de las Indias. Biblioteca de Autores Españoles T. CXVII. Edición y estudio preliminar de Juan Pérez de Tudela Bueso. Ed. Atlas, Madrid.

Pané, Fray Ramón

1974[¿1498?] Relación acerca de las Antigüedades de los Indios: el primer tratado escrito en América. Nueva versión con notas, mapa y apéndices por José Juan Arrom. Siglo XXI Editores, S.A., México.

\section{Nota}

1 Publicado por primera vez en la revista Cultura Universitaria, LXVI-LXVII. 1959, enero-febrero. Caracas: 97-104, y después recopilado en su obra Estudios sobre Bartolomé de Las Casas, Ed. Península, Barcelona, 1976: 291-300. 
